merit of intraoperative intrathoracic ultrasonography, which has been reported for localization of lung tumors, ${ }^{4}$ may be greater for vascular lesions. Color Doppler ultrasonography would be more informative, although we could not use it.

Although in this case we did not use an endosurgical stapler for fear of sudden massive bleeding in case of incomplete stapling or tear of the pleura along the staple line, the lesion may have been resectable by stapling. Also, permanent occliusion of the blood flow of a PAVF by an endosurgical stapler without a knife may be possible if the lesion is small enough. Three ports and utility thoracotomy taken together are not much smaller than a conventional axillary thoracotomy, but we considered it important to avoid rib spreading. Furthermore, with more experience, we could use an endosurgical clamp to occlude the pulmonary blood flow without utility thoracotomy. In our case, at least, all the goals of the conventional approach of surgical excision of PAVF by thoracotomy were accomplished with the video-assisted thoracoscopic surgical approach. Because PAVFs are usually close to the visceral pleura, ${ }^{5}$ video-assisted thoracoscopic surgical intervention may become the treatment of choice.

\section{REFERENCES}

1. Hartnell GG, Allison DJ. Coil embolization in the treatment of pulmonary arteriovenous malformations. J Thorac Imaging $1989 ; 4: 81-5$.

2. White RI Jr, Lynch-Nyhan A, Terry P, Buescher PC, Farmlett EJ, Charnas L, et al. Pulmonary arteriovenous malformations: techniques and long-term outcome of embolotherapy. Radiology 1988;169:663-9.

3. Puskas JD, Allen MS, Moncure AC, Wain JC Jr, Hilgenberg $\mathrm{AD}$, Wright $\mathrm{C}$, et al. Pulmonary arteriovenous malformations: therapeutic options. Ann Thorac Surg 1993;56:253-7.

4. Shennib H, Bret P. Intraoperative transthoracic ultrasonographic localization of occult lung lesions. Ann Thorac Surg 1993;55:767-9.

5. Burke CM, Safai C, Nelson DP, Raffin TA. Pulmonary arteriovenous malformations: a critical update. Am Rev Respir Dis 1986;134:334-9.

\title{
BRONCHIAL NECROSIS INDUCED BY INHALATION OF AN IRON TABLET
}

Gérard Babatasi, MD, ${ }^{a}$ Massimo Massetti, MD, ${ }^{\mathrm{a}}$ Françoise Galateau, MD, ${ }^{\mathrm{b}}$ Brigitte Mosquet, MD, ${ }^{\mathrm{b}}$ André Khayat, MD, ${ }^{a}$ and Claude Evrard, MD, ${ }^{a}$ Caen, France

The late occurrence of bronchial stenosis after inhalation of iron tablets has been described. Inhalation of iron tablets causes rare tissue necrosis caused by local release of cytotoxic oxidant radicals, which results in bronchial perforation. We observed a dramatic early complication in the form of acute bronchial necrosis in two patients, who required pulmonary resection. In this report we review the literature concerning this topic. We stress that early diagnosis and management (bronchoscopy) are mandatory to avoid caustic bronchial erosion.

Case reports. CASE 1. A 59-year-old woman consulted a physician 4 days after inhalation of a ferrous sulphate tablet. She was taking Tardyferon tablets ( 1 brownish pink-coated tablet 4 times a day; ferrous sulphate 256.26

From the Thoracic and Cardiovascular Surgery Department ${ }^{\mathrm{a}}$ and the Department of Pathology, ${ }^{\mathrm{b}}$ University Hospital Caen-côte de Nacre, Caen, France.

Received for publication Feb. 26, 1996; accepted for publication April 1, 1996.

Address for reprints: G. Babatasi, MD, Thoracic and Cardiovascular Surgery Department, University Hospital Caen-côte de Nacre, 14033-Caen, France.

J Thorac Cardiovasc Surg 1996;112:1397-9

Copyright (C) 1996 by Mosby-Year Book, Inc.

$0022-5223 / 96 \$ 5.00+0 \quad \mathbf{1 2 / 5 4 / 7 3 9 1 8}$ $\mathrm{mg}$, mucoprotease $80 \mathrm{mg}$, and ascorbic acid $30 \mathrm{mg}$; Laboratoires Robapharm, Les Ulis, France) for mild anemia. A fiberoptic bronchoscopic examination revealed, after extraction of the tablet, a necrotic and inflammatory process of the mucosa of the right distal bronchus. Four days later, a second bronchoscopic examination showed inflammatory lesions of the right intermediate bronchus with patchy necrosis of the mucosa.

Nine days after the first consultation, the patient reported two episodes of hemoptysis and was transferred to our thoracic unit. Chest examination showed wheezing and decreased air entry. Chest roentgenography revealed collapse of the right lower lobe. Another episode of hemoptysis caused hypovolemic shock and necessitated bronchoscopy, which showed a polypoid mass and ulceration in the bronchial posterior zone. Five hours later, cardiac arrest occurred as a result of massive hemoptysis and an emergency thoracotomy was required. The right lung was entirely filled with blood and despite clamping of the pulmonary artery and pneumonectomy, the patient died. Massive necrosis with $1.5 \mathrm{~cm}$ long ulceration of the right intermediate bronchus and of the walls of both the pulmonary artery and the right upper vein were observed.

CASE 2. A 54-year-old man with a history of neonatal hypoxia and spastic paraplegia as a sequela was admitted to the emergency department because of vigorous coughing that produced a cupful of blood. The patient had a hiatal 


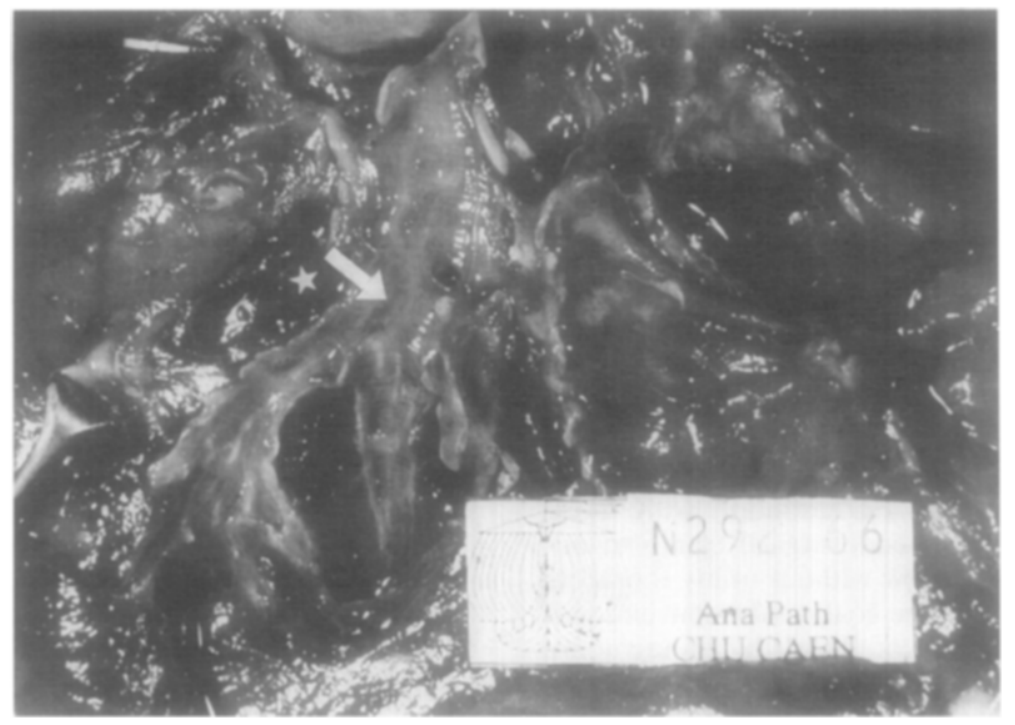

Fig. 1. Longitudinal open section of left lower bronchus in case 2. White arrow indicates inflammatory process with caustic erosion of bronchial wall; white star indicates focal area of alveolar hemorrhage beneath bronchial caustic erosion.

hernia with chronic blood loss and iron-deficiency anemia, and for this reason was treated with Tardyferon iron tablets. On admission to our department, the patient had chest pain with a nonproductive cough. The medical team determined a specific episode of aspiration 8 hours before. Localized rhonchi were found on the chest examination. The chest roentgenogram showed patchy opacification in the left midzones.

Bronchoscopy was done and showed total occlusion of the left lower bronchus by a polypoid mass covered with greenish-brown necrotic material, which could not be removed by bronchoscopy. The proximal part of the left lower bronchus was inflamed and necrotic. Otherwise, the right main bronchus was entirely normal. The patient was taken to the operating room for emergency operation. At bronchotomy, macroscopic lesions of the left lower bronchus were clearly identifiable (Fig. 1) and circumferential caustic erosion with local necrosis was found. A left lower lobectomy was done after local bronchial lavage with $1 \%$ bicarbonate saline solution. The postoperative course was uneventful. Bronchoscopy 4 weeks after operation did not reveal any anomaly. The patient was free from the earlier respiratory symptoms at 6 months.

Discussion. Early complications of inhaled foreign bodies ${ }^{1}$ such as asphyxia, life-threatening dyspnea, laryngeal edema, and hemoptysis and late complications such as bronchial stenosis ${ }^{2,3}$ can be avoided with early diagnosis and active primary care. These principles should be applied to cases of inhalation of ferrous sulphate tablets, ${ }^{4,5}$ which may also cause serious complications. The importance of removal of the tablet on an emergency basis is shown in the first case. The caustic necrosis of the bronchus and of the wall of the arteries was explained by induction of local production of cytotoxic oxidant radicals.
The heavy concentration of ferrous acid on $1 \times 2 \mathrm{~cm}^{2}$ of bronchial mucosa explained the necrotic process.

Few cases of aspiration of ferrous sulphate tablets have been reported in the literature. The site of a foreign body aspiration is mainly into the right lung with the tablet located in the intermediate bronchus. In our second patient, probably because of excess coughing, the tablet was located in the left lower bronchus. Determining the history in cases of aspiration is easy with an adult patient, though more difficult in elderly patients or those with cerebral deficiency. A normal finding on chest $\mathrm{x}$-ray films does not exclude foreign-body inhalation, and patients with suggestive histories or with abnormalities on chest examination should undergo bronchoscopy, which is the treatment of choice. In one previously published case, ${ }^{5}$ a severe bronchial stenosis in a 60 -year-old woman necessitated right middle and lower lobectomies 8 months after iron tablet aspiration. Removal of the tablet at the initial bronchoscopy was not possible in our second patient, and local caustic erosion was seen after bronchial lavage with $1 \%$ bicarbonate saline solution.

Experience suggests persistence of hemoptysis and fever and a delay between aspiration and the bronchoscopic findings indicate the need for thoracotomy and bronchotomy to avoid fatal complications. These are the only two cases described with bronchial necrosis and alveolar hemorrhage and one of these reports the only case of a patient who survived after this severe complication caused by inhalation of a ferrous sulphate tablet. The piece of the left lower lobe resected (Fig. 1) showed necrosis of the bronchial epithelium and of the underlying tissues, with brownish features suggesting the presence of ferrous pigments. Extension of transmural bronchial necrosis was observed along the resected left distal bronchial tree, with 
alveolar hemorrhage next to the bronchus. Fragments of necrotic fibrous connective tissue were encrusted with golden-brown pigment that showed a strong reaction for ferric iron (Perls's coloration and Prussian blue).

To avoid such effects, clinicians caring for elderly patients should make sure that tablets are taken while sitting. Acute respiratory symptoms and hemoptysis in elderly patients can be a result of tablet inhalation. If removal of the iron tablet is not possible, a thoracotomy with bronchotomy, segmental resection, or lobectomy is indicated. ${ }^{5}$ Anesthetists, bronchoscopists, and cardiothoracic surgeons must act together.
2. Godden DJ, Kerr KM, Watt SJ, Legge JS. Iron lung: bronchoscopic and pathological consequences of aspiration of ferrous sulphate. Thorax 1991;46:142-3.

3. Lamaze R, Tréchot $P$, Martinet $Y$. Bronchial necrosis and granuloma induced by the aspiration of a tablet of ferrous sulphate. Eur Respir J 1994;7:1710-1.

4. Mizuki M, Onizuka O, Aoki T, Tsuda T. A case of remarkable bronchial stenosis due to aspiration of delayed-release irontablet (in Japanese with English abstract). Nippon Kyobu Shikkan Gakkai Zasshi 1989;27:234-9.

5. Tarkka M, Anttila S, Sutinen S. Bronchial stenosis after aspiration of an iron tablet. Chest 1988;93:439-41.

\section{COMPLICATIONS OF FEMORAL ARTERY CANNULATION FOR PERIOPERATIVE MONITORING IN CHILDREN}

Keith C. Kocis, MD, MSc, ${ }^{a}$ Roger P. Vermilion, MD, ${ }^{b}$ Louise B. Callow, RN, MSN, ${ }^{c}$ Thomas J. Kulik, MD, Achi Ludomirsky, MD, ${ }^{\mathrm{b}}$ and Edward L. Bove, MD, ${ }^{\mathrm{c}}$ Baltimore, Md., and Ann Arbor, Mich.

Arterial monitoring is essential for the perioperative treatment of children undergoing repair of congenital cardiac defects. Peripheral arterial cannulation in small children can be difficult, and catheter-related complications are common. ${ }^{1}$ For these reasons, femoral arterial cannulation is frequently performed. According to clinical criteria, the incidence of femoral artery complications (ischemia, thrombosis, embolism, and infection) after cannulation in children is between $0.1 \%$ and $14 \%{ }^{2}$ Clinical criteria are known to be insensitive, however, in the diagnosis of femoral artery obstruction in children. ${ }^{3-5}$ Ultrasonography has been shown to be sensitive and specific for the diagnosis of femoral artery obstruction. By means of ultrasonography, we recently demonstrated a $33 \%$ incidence of femoral artery obstruction among infants after cardiac catheterization ${ }^{3}$ and a $26 \%$ prevalence among children undergoing transfemoral arterial balloon angioplasty or valvuloplasty. ${ }^{4}$ The purposes of this study were to prospectively determine the prevalence of and predictors for complications of femoral artery cannulation for perioperative monitoring in children.

From the Department of Anesthesiology and Critical Care Medicine, The Johns Hopkins Medical Institutions, Baltimore, ${ }^{a}$ and Departments of Pediatrics ${ }^{\mathrm{b}}$ and Surgery, ${ }^{\mathrm{c}}$ University of Michigan Medical Center, Ann Arbor, Mich.

Received for publication Jan. 22, 1996; accepted for publication Feb. 2, 1996.

J Thorac Cardiovasc Surg 1996;112:1399-1400

Copyright (C) 1996 by Mosby-Year Book, Inc.

$0022-5223 / 96 \$ 5.00+0 \quad \mathbf{1 2 / 5 4 / 7 2 5 6 4}$
Thirty consecutive children with a mean age of $19 \pm 7$ months (median 5.3 months, range 1 day to 13 years) were entered prospectively into this study after femoral artery cannulation for perioperative arterial monitoring. The children's mean weight was $9.5 \pm 2.4 \mathrm{~kg}$ (median $5.4 \mathrm{~kg}$ ). Ten patients underwent palliative operations (including hemi-Fontan or Fontan operations); 20 underwent corrective operations. In the operating room, the femoral artery was cannulated percutaneously in 24 patients and by cutdown in six patients with a 22 gauge 1.38 -inch polyurethane catheter (Arrow International, Inc., Reading, $\mathrm{Pa}$.). Heparinized fluid was infused through the catheters. The femoral arteries were cannulated for $6.9 \pm$ 1.5 days (median 4 days, range 0.5 to 35 days). Indications for catheter removal and catheter complications, as diagnosed by clinical criteria (ischemia, peripheral embolism, hemorrhage, infection, and other), were recorded. Both femoral arteries were evaluated with ultrasonography $3.5 \pm 0.4$ days (range 0 to 11 days) after catheter removal. Femoral artery obstruction was diagnosed according to previously described criteria. ${ }^{3}$ The demographic and clinical data (age, weight, height, diagnosis, type of operation [palliative or corrective], previous cardiac catheterization, previous femoral artery cannulation, insertion technique [percutaneous or surgical cutdown], and duration of arterial cannulation) were collected, combined with outcome measures (clinical complications and ultrasonographic results), and analyzed with univariate and multivariate logistic regression modeling techniques.

Clinically, two (7\%, 95\% confidence interval $0 \%$ to $16 \%$ ) femoral artery complications occurred (Table I, patients 1 and 2). By means of ultrasonography, six patients (20\%) 